\title{
Total Microbial Populations in Air-Conditioned Spaces of a Scientific Museum: Precautions Related to Biodeterioration of Scientific Collections
}

\author{
Antonio Carlos Augusto da Costa*, Lucia Alves da Silva Lino and Ozana Hannesch \\ Museum of Astronomy and Related Sciences, Department of Documentation and Archives, 586 Rua General Bruce, S. Christopher, Rio de Janeiro,
} Brazil

\section{Abstract}

Air-conditioned areas of a museum were monitored for the presence of total microbes in the air. The results were evaluated based on a Brazilian resolution that regulates accepted contamination levels in air-conditioned spaces, as well as based on the parameters from the World Health Organization. The results indicated low levels of bacterial and fungal populations in four distinct spaces, with total counts smaller than $50 \mathrm{CFU} \mathrm{m}^{-3}$. These results, compared to the monitoring performed in the outside area of the museum indicated a very low internal to external count ratio, the highest one around 0.131 , a value far beyond the acceptable limit of 1.5 , as predicted by the Brazilian legislation. Even though those values clearly indicate low levels of contamination for human comfort, in the spaces monitored, the marked presence of fungi from the genera Cladosporium, Aspergillus and Penicillium deserve particularly attention due to their possible cellulolytic activity. The spaces are permanently controlled for their temperature and relative humidity levels, to be used as a permanent repository for scientific and historical documents in Brazil, and the presence of these potential cellulose-degrading microbes can markedly jeopardize the effective occupation of the areas due to their biodeterioration effects.
\end{abstract}

Keywords: Cladosporium; Aspergillus; Penicillium; Museum; Cellulolytic activity; CFU counting

\section{Introduction}

Microbiological monitoring of air-conditioned environments has become a common practice throughout the world, particularly in areas designed to keep important paper collections, such as museums and archives. It is known that microorganisms of various types are present in the environment, often associated with particulate matter resulting from the lack of preventive and corrective maintenance services of airconditioners [1,2].

Pasanema et al. [3] investigated fungal growth and the maintenance of its viability in building materials under controlled humidity. The materials were subjected to various environmental conditions with varying absorption of water and relative humidities. After appropriate treatment, the authors observed the proliferation of fungi and actinomycetes, after two weeks of incubation. The results showed that when water was absorbed by capillary action, fungal growth was faster in early wood-based materials under $20 \%(\mathrm{w} / \mathrm{v})$ humidity. Condensation under varying humidity and temperature was responsible for the the rapid growth of different fungal populations, particularly under high humidities. It is noteworthy that the fungal species were particularly tolerant to fluctuations in temperature and humidity, with very little effect viability.

Hyvarinena et al. [4] studied the diversity of fungi and actinomycetes in spaces designed with building materials of different natures, amenable to turn into microenvironments for their proliferation. In particular, cellulosic materials and ceramics, paints and plastics, in a clear state of decomposition, were evaluated for the presence of microbial populations. The authors found approximately $100 \mathrm{CFU} \mathrm{g}^{-1}$ (Colony Forming Units per gram of material), with the largest microbial populations associated with the presence of ligno-cellulosic and paperbased materials. The authors also observed that bacterial populations were lower than fungal populations, in contrast to the great fungal diversity, particularly of the genus Penicillium, as well as a great number of yeasts. In paper-based materials the main fungal genera found were Cladosporium and Stachybotrys; in glues and paints the most prevalent genus was Acremonium and the species Aspergillus versicolor. Accord- ing to the authors, the main contribution of that research was to show the association between microbial growth and its occurrence in building materials of different nature. In particular, the authors highlighted a certain degree of specificity between the type of material and the predominant fungal genera.

Nielsena et al. [5] studied the influence of relative humidity and temperature on the growth and metabolism of selected fungal species in various types of building materials. The authors evaluated the microbial metabolic diversity, after incubation of several samples of building materials based on wood, starch and composite materials, at temperatures varying from 5 to $25 \mathrm{oC}$, under 69 to $95 \%$ relative humidity, during seven months. The authors observed a high diversity of species present on the materials, with a prevalence of the genera Penicillium, Aspergillus and Eurotium, all of them mycotoxins producers.

Giannantonio et al. [6] observed the presence of incrustations on concrete surface, under controlled laboratory conditions, due to the direct action of the fungal genera Alternaria, Cladosporium, Epicoccum, Fusarium, Mucor, Penicillium, Pestalotiopsis and Trichoderma on the concrete.

Hoang et al. [7] evaluated the susceptibility of "green" building materials to biodeterioration by Aspergillus niger, an indoor reference fungus. The detection of spores and the presence of external compounds acting as nutrients contributed to the growth of Aspergillus niger on

*Corresponding author: Antonio Carlos Augusto da Costa ,State University of Rio de Janeiro,Institute of Chemistry, Department of Biochemical Process Technology,Rua São Francisco Xavier 524, Rio de Janeiro, Brazil, CEP: 20550013,Tel: 55-21-23340000; E-mail: antoniocosta2010@gmail.com

Received September 12, 2011; Accepted October 22, 2011; Published Octobe 24, 2011

Citation: Augusto da Costa AC, da Silva Lino LA, Hannesch O (2011) Tota Microbial Populations in Air-Conditioned Spaces of a Scientific Museum: Precautions Related to Biodeterioration of Scientific Collections. J Bioprocess Biotechniq 1:106 doi: 10.4172/2155-9821.1000106

Copyright: (c) 2011 Augusto da Costa AC, et al. This is an open-access article distributed under the terms of the Creative Commons Attribution License, which permits unrestricted use, distribution, and reproduction in any medium, provided the original author and source are credited. 
walls and ceilings gypsum. The authors found a strong correlation between the content of the mixture and organic materials by observing the time for coating of $50 \%$ of surface area by fungi. The results suggested that the presence of organic matter in a given material appears to be an important factor for the diagnosis of fungal susceptibility to a subsequent possible biodeterioration. Not only the materials are responsible for the spread of fungal spores and bacteria, but also the climatic conditions that regulate the environment, internally or externally.

Aira et al. [8] found some fungi in the architectural complex of the Cathedral of Santiago de Compostela in Spain, observing the presence of 35 different genera, mainly Alternaria, Aspergillus, Cladosporium and Penicillium. Interestingly, the authors did not find differences between populations inside and outside the Cathedral, with a maximum occurrence between spring and summer. The amount of fungi found was relatively small at various points of the central nave of the Cathedral, while in Corticela Chapel this number reached 6,500CFU $\mathrm{m}^{-3}$. There was also a higher incidence of microorganisms around 13:00 $\mathrm{h}$ (around $400 \mathrm{CFU} \mathrm{m}^{-3}$ ), where the flow of visitors reaches a peak.

Mesquita et al. [9] used advanced techniques of molecular biology to elucidate the fungal morphology and to evaluate the infection of historical documents. The researchers identified a wide diversity of fungi, on parchment, laid and wood pulp paper. Authors identified fourteen genera of fungi, the most frequent Cladosporium, Penicillium and Aspergillus, and less abundantly the presence of the genera Alternaria, Botrytis, Chaetomium, Chromelosporium, Epicoccum, Phlebiopsys and Toxicocladosporium.

Abe [10] found fungal contamination of materials stored in an art museum, which was monitored according to a biological index related to climatic parameters, giving an indication of the environmental capacity to maintain and proliferate fungal cells. To determine this index, fungal spores were encapsulated, followed by the observation of the germination of spores, and measurements of the extent of fungal hyphae. The authors identified a predominant occurrence of Aspergillus and Eurotium penicillioides. A number of other microbial populations is reported in the literature, specific to intrinsic characteristics of materials where populations grow, as well as with environmental factors that regulate proliferation.

All these studies suggest that the microorganisms that colonize building materials or are commonly found in the air are the same microbes that create microenvironments that colonize surfaces, including those consisting of lignocellulosic materials, such as documentary collections.

Thus, it is important to predict, for practical purposes, the effects of archives transfers between areas under different climate conditions. Given the wide distribution of microbial species in environments subject to temperature and relative humidity control, the objective of this study was to quantify fungi and bacteria in four selected rooms from the Museum of Astronomy and Related Sciences, for purposes of qualification of the area and also to evaluate the effect of transferring collections between rooms under distinct climate conditions. The final evaluation will be based on Brazilian Anvisa Resolution 176/2000, a resolution that presents reference standards for indoor air quality in climate-controlled spaces.

\section{Materials and Method}

\section{Monitored areas}

The Museum of Astronomy and Related Sciences (MAST) is locat- ed in the Imperial Quarter of São Cristóvão, Rio de Janeiro City, and is responsible for the safety and custody of scientific archives from Brazilian researchers and institutions. Four selected rooms from the Coordination of Documentation and Archives (CDA) from the MAST, located in the basement of the building, in September 2010, as well as internal offices and external areas were selected for the monitoring of microbial growth, as represented in Figure 1.

Sample collection was performed every meter of each space, according to the Anvisa Resolution 176/2000. At each sampling point two open Petri dishes were placed, each one containing the appropriate culture medium, under the air conditioning system on. This resolution intends to reach the "Technical guidance on standards benchmarks indoor air quality in climate-controlled environments for public use, as regards the setting of maximum recommended values for biological, chemical and physical parameters of indoor air, the identification of pollution sources of biological, chemical and physical analytical methods and recommendations for control". Only microbiological parameters were investigated, since Resolution 176/2000 also recommends monitoring the chemical environment. The number of samples collected in each area is presented in Table 1.

Control samples (EXT) are those from environments where it is expected a high incidence of bacterial and fungal populations (outdoors, negative control). Samples from indoor environments (LAB, ESC, HIG, ENC, positive controls), are from areas where it is expected a low microbial contamination due to the characteristics of the area. All the samples were collected in duplicate.

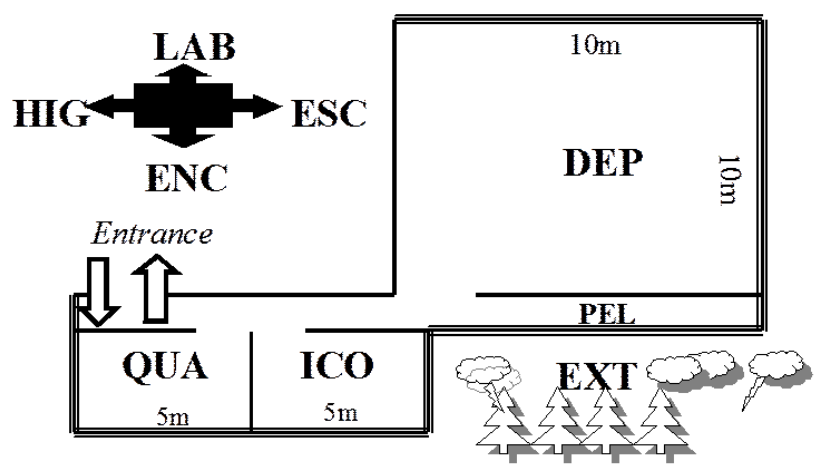

Figure 1: Schematic representation of the monitored areas of CDA/MAST, located in the basement of the building for the Conservation of Collections Legend: Downstairs: QUA (Quarantine Room), ICO (Iconography Room), PEL (Film Storage Room); DEP (Repository of Collections Room). Upstairs: LAB (Research Laboratories); ESC (Offices); HIG (Hygienisation Laboratory); ENC (Book Binding Room). Outside the building: EXT (External Area).

\begin{tabular}{|c|c|}
\hline Environment & Number of samples \\
\hline QUA & 20 \\
\hline ICO & 20 \\
\hline PEL & 20 \\
\hline DEP & 40 \\
\hline LAB & 05 \\
\hline HIG & 05 \\
\hline ENC & 05 \\
\hline ESC & 05 \\
\hline EXT & 10 \\
\hline
\end{tabular}

Table 1: Total samples collected in the monitored areas of the CDA/MAST for microbiological monitoring. 
Citation: Augusto da Costa AC, da Silva Lino LA, Hannesch O (2011) Total Microbial Populations in Air-Conditioned Spaces of a Scientific Museum: Precautions Related to Biodeterioration of Scientific Collections. J Bioprocess Biotechniq 1:106 doi: 10.4172/2155-9821.1000106

Page 3 of 6

\section{Reference standards}

The reference standards adopted according to Anvisa Resolution 176/2000 were: The maximum recommended value for microbiological

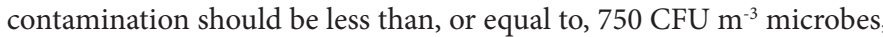
for an $\mathrm{I} / \mathrm{E}$ ratio smaller than or equal to 1.5 , where $\mathrm{I}$ is the amount of microbes in the indoor environment and $\mathrm{E}$ is the amount of microbes in the outdoor environment. When the I/E ratio is greater than or equal to 1.5 , it is necessary to diagnose the sources for corrective actions.

\section{Culture media for fungi and bacteria}

The culture media used were PCA (Plate Count Agar, Merck, Darmstadt, Germany) for the quantification of total bacteria and PDA (Potato Dextrose Agar, Darmstadt, Germany) for quantification of total fungi. The media were dissolved in distilled water, autoclaved at $121^{\circ} \mathrm{C}$ for 20 minutes, distributed in sterile Petri dishes and solidified after cooling.

\section{Sampling}

Two Petri dishes were distributed to each square meter of each room monitored, as well as in the areas that represent positive and negative controls. For each point indicated one set of two Petri dishes were placed for the quantification of total heterotrophic bacteria and one set for the quantification of total fungi. The Petri dishes were distributed at the sampling points, opened at approximately $3 \mathrm{~m}$ below the output of central air-conditioners, for two hours. Direct impact of the air over the medium contained in Petri dishes was responsible for the dissemination of the microbial cells. The samples were incubated (Incubator New Ethics, Model D-411, São Paulo, Brazil) at temperatures adjusted to grow bacteria $\left(35^{\circ} \mathrm{C}\right)$ and fungi $\left(25^{\circ} \mathrm{C}\right)$, for two and seven days, respectively. Colonies were counted using a colony counter coupled to a magnifying glass and digital record of the data (Phoenix, Model CP600, São Paulo, Brazil). For each space average values of quantification were reported.

\section{Results and Discussion}

Figure 2 presents the results of the quantification of fungi in the reported areas.It can be observed that, except for the external environment (EXT) the remaining areas showed a low average concentration of fungi, ranging from 4.4 to $16.8 \mathrm{CFU} \mathrm{m}$-3in the areas QUA, ICO, PEL and DEP. Values ranged from 0.4 to $2.2 \mathrm{CFU} / \mathrm{m}^{3}$ in the administrative and laboratory areas (LAB, HIG, ENC and ESC). These values are extremely low compared with values obtained in the external environment (greater than $300 \mathrm{CFU} \mathrm{m} \mathrm{m}^{-3}$ ). This indicates that the values of the relationships I/E is low, as shown in Table 2.

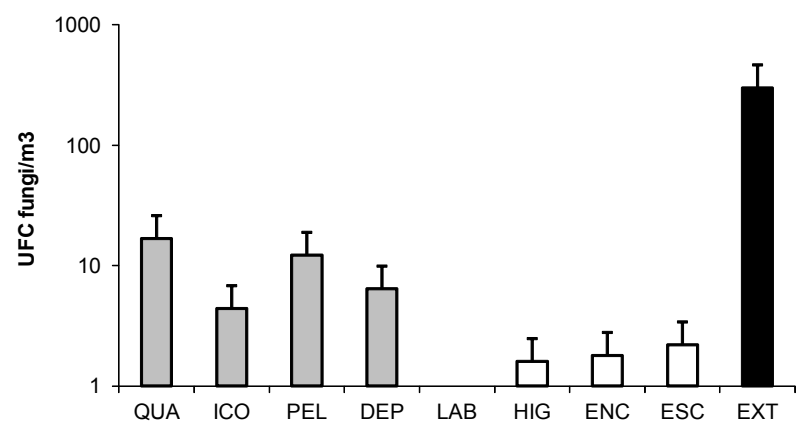

Figure 2: Quantification of fungal colonies in the selected areas of the CDA/ MAST. Bars represent average standard deviations.
* For purposes of calculation, the reference value for the external environment (EXT) was considered $300 \mathrm{UFC} / \mathrm{m}^{3}$, as recommended by most microbiological reviews.

The results indicate that the results of the I/E ratio were extremely low, indicating that the selected areas are in perfect condition for the movement of staff, according to the Anvisa Resolution 176/2000. Moreover, in all cases, the concentration of microorganisms was smaller than $750 \mathrm{CFU} \mathrm{m}{ }^{-3}$. This indicates that both criteria from the Resolution were observed, corroborating that the rooms from the CDA/MAST are suitable with respectto indoor air quality and the setting of maximum recommended for biological contamination. From microscopical observation and colony characteristics it can be concluded that colonies from the genera Cladosporium, Aspergillus and Penicillium predominate. These observations are not conclusive and must be confirmed by DNA tests or complementary genotypic assessments. It is important to mention that those genera are the most typical fungi found in these environments.

Jaffal et al. [11] using a mechanical air samples for the enumation of fungal CFU in residential environments, found five groups of fungi, ainly members of the genus Aspergillus. The authors concluded that although their high numbers, the fungal cells presented little effect on human health.

As well, Shelton et al. [12] examined 12,026 fungal air samples (9,619 indoor samples and 2,407 outdoor samples) from 1,717 buildings located across the United States; these samples were collected during indoor air quality investigations performed from 1996 to 1998 . The most common culturable airborne fungi, both indoors and outdoors and in all seasons and regions, were Cladosporium, Penicillium, nonsporulating fungi, and Aspergillus. Stachybotrys chartarum was identified in the indoor air in $6 \%$ of the buildings studied and in the outdoor air of $1 \%$ of the buildings studied.

\begin{tabular}{|c|c|}
\hline Room & I/E Ratio* \\
\hline QUA & 0.056 \\
\hline ICO & 0.015 \\
\hline PEL & 0.040 \\
\hline DEP & 0.021 \\
\hline LAB & 0.001 \\
\hline HIG & 0.005 \\
\hline ENC & 0.006 \\
\hline ESC & 0.007 \\
\hline
\end{tabular}

Table 2: I/E ratio obtained for fungal contamination in selected areas of the CDA/ MAST.

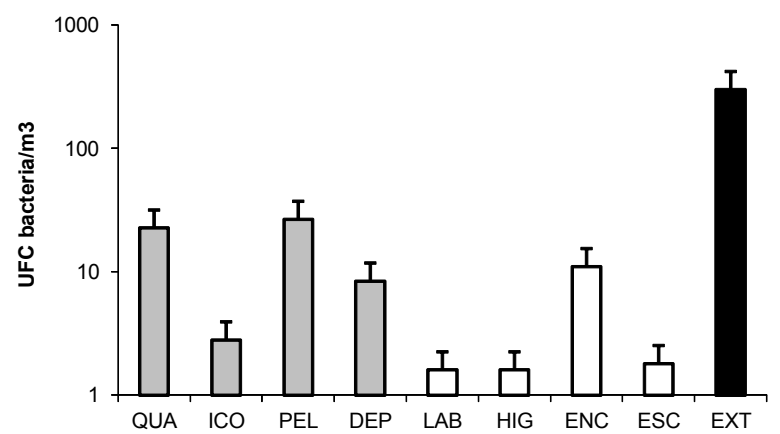

Figure 3: Quantification of bacterial colonies in the selected areas of the CDA MAST. Bars represent average standard deviations. 
Similarly, Figure 3 presents the results of the quantification of bacterial populations in the same environments. Quantification of bacterial populations presented similar values in comparison to fungal populations, with small differences between populations inside the same environment. Thus, the relationships I/E remained practically the same, also in accordance to Anvisa Resolution 176/2000. This means that the environments monitored presented bacterial populations in equivalent quantities as fungal populations, although fungi have a remarkable role in the degradation of cellulose through their cellulolytic enzymes.

Unlike fungi, phenotypic analysis of the grown bacterial populations did not identify the most representative groups. One conclusion that can be drawn about the presence of bacterial populations in the same proportion as observed for fungal populations, is due to the highest specificity of the PCA culture medium, and the small size of the colonies, typically observed in bacterial growth in this culture medium [13].

Anvisa Resolution 176/2000 does not specify between bacterial and fungal populations to characterize the microbial population quantified. Indeed, for purposes of environmental monitoring of air conditioned environments, there is increasing concern about fungal populations due to their natural ability to produce spores, which can be easily disseminated by ducts and pipes of air-conditioning systems. However, the ability to produce spores is not a unique feature of fungi, this property being also characteristic of some bacterial strains. Nevertheless, this property is much less common in bacterial than in fungal structures, supporting the ongoing concern about the monitoring of fungi, often neglecting the occurrence of bacteria. Because the Anvisa Resolution $176 / 200$ does not state clear boundaries for that matter, we proceeded to quantify the overall fungal and bacterial populations, as depicted in Figure 4.

It is noteworthy from Figure 4, even considering the sum of bacterial and fungal populations, that all environments are in accordance to the Anvisa Resolution 176/2000, for microbial populations (bacteria

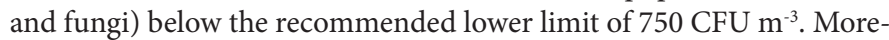
over, the I/E ratio is still far below the limit value of 1.5 , confirming the suitability of the environment for the movement of staff. Table 3 presents the I/E ratio for the total microbial populations quantified.

These results show that the relationships I/E are in a range of extremely low values, confirming that all environments are suitable for the human comfort, as required by Anvisa Resolution. It is noteworthy that the largest I/E ratio was equal to 0.131 , less than $10 \%$ of the value that would characterize the environment as an environment corrective actions are needed.

However, it must be stressed that these particular environments

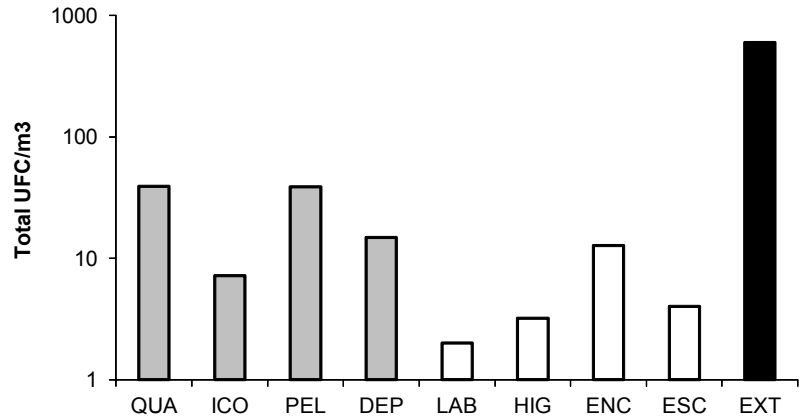

Figure 4: Quantification of total colonies in the selected areas of the CDA/MAST. Bars represent average standard deviations.

\begin{tabular}{|c|c|}
\hline Room & I/E Ratio* \\
\hline QUA & 0.131 \\
\hline ICO & 0.024 \\
\hline PEL & 0.129 \\
\hline DEP & 0.049 \\
\hline LAB & 0.006 \\
\hline HIG & 0.010 \\
\hline ENC & 0.042 \\
\hline ESC & 0.013 \\
\hline
\end{tabular}

Table 3: I/E ratio for total microbial contamination in selected areas of the CDA MAST

were monitored for handling and storage of papers and archives of historical nature, subject to deterioration from chemical, physical or microbiological attack. The microbiological attack can result from excessive proliferation of bacterial and fungal species according to the malfunctioning of air conditioners and humidity controllers.

* For purposes of calculation, the reference value for the external environment (EXT) was considered $300 \mathrm{UFC} / \mathrm{m}^{3}$, as recommended by most microbiological reviews.

Particulate matter suspended in the indoor and outdoor atmosphere are potential carriers of microorganisms, being responsible for microbiological contamination is observed in most artificially cooled environments. Brickus et al. [14] observed concentrations of particulate matter between 42.7 and $91.7 \mathrm{mg} \mathrm{m}^{-3}$ for indoor air and between 39.9 and $151.0 \mathrm{mg} \mathrm{m}-3$ for the outside air in office environments on several floors of a commercial building. The authors use the same I/E ratio to evaluate the air quality. It can be observed from the data discussed above that, probably in many environments, the I/E ratio is above the value of 1.5. In addition to this high value of $\mathrm{I} / \mathrm{E}$ ratio Brazilian CONAMA established a maximum value of $80 \mathrm{mg} \mathrm{m}^{-3}$ for particulate matter concentration in the air. One must consider that in 1997 the Anvisa Resolution 176/2000 not yet published, this being an adaptation of the current limits in the 90's. The following year, Dantas [15] conducted a thorough review of the weather conditions as agents of chemical, physical and biological integrity of air-conditioning systems through its transport system, with corrective solutions when identifying risk associated with each of the factors described.

Kulcsar Neto and Siqueira [16] suggested reference standards for microbiological quality in interiors, both in terms of quality and quantity. The authors state that it is not acceptable the presence of the following pathogenic species or toxigenic fungus: Histoplasma capsulatum, Cryptococcus neoformans, Paracoccidioides brasiliensis, Aspergillus fumigatus, Aspergillus parasiticus, Aspergillus flavus, Stachybotrys atra and Fusarium moniliforme.

When bacteria are considered, it is not allowed in indoor environments the presence of Legionella pneumophila (present in the condensation water air-conditioning and not associated with particulate matter) and Gram-negative pseudomonads. The authors consider the possibility of naturally occurring Gram-positive bacteria of the genera Micrococcus, Streptococcus and Staphylococcus. Although there is no consensus in the literature, some authors propose an acceptable concentration of fungal spores indoors up to $1,000 \mathrm{CFU} \mathrm{m}^{-3}$, although there are obvious signs of impairment of health, with the occurrence of allergic alveolitis associated with fungal concentrations below this value. With regard to bacterial populations there are different reference standards, as this proposed by Toth [17]: for bacteria that inhabit the human tract without causing damage or disease, the author suggests the limit of $200 \mathrm{CFU} \mathrm{\textrm {m } ^ { - 3 }}$ 
Citation: Augusto da Costa AC, da Silva Lino LA, Hannesch O (2011) Total Microbial Populations in Air-Conditioned Spaces of a Scientific Museum: Precautions Related to Biodeterioration of Scientific Collections. J Bioprocess Biotechniq 1:106 doi: 10.4172/2155-9821.1000106

Page 5 of 6

Hood [18] suggests a limit of $500 \mathrm{CFU} / \mathrm{m}^{3}$ for the presence of Gram-negative, attempting for the need for maintenance of air-conditioning systems.

There are also the limits recommended by the World Health Organization, with different criteria, all more restrictive than those previously mentioned, which will be only briefly mentioned: (a) to 50 CFU $\mathrm{m}-3$ should proceed to a prompt investigation, if the fungus is unique, (b) Up to $150 \mathrm{CFU} \mathrm{m} \mathrm{m}^{-3}$ if the presence of more than one species, (c)

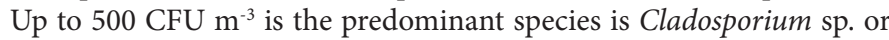
other fungi commonly found in the environment. There are also other parameters that consider the occurrence of other species such as Alternaria sp., which will not be described here. With respect to bacteria the authors mention the lack of knowledge and monitoring for artificially air conditioned environments. Anyway, even considering the parameters suggested by $\mathrm{WHO}$, the present results are in accordance to this rule.

Bortoletto [19] reports the presence of fungal contamination in a large library due problems related to control of the heating and airconditioning system and air humidity, which gave rise to outbreaks of occurrence of fungi, whose removal was being done in a manner concomitant with the repair of the cooling system. After the outbreaks structural interventions, corrective and preventive actions have been suggested, which included fumigation of environments for inactivation of fungal structures, complete cleaning of the ducts by mechanical cleaning, followed by a new fumigation after washing. Books in the collection found in the monitored environment presented fungal cells of Aspergillus, Penicillium, Cladosporium and Trichoderm, all present in the environments selected from the library, with populations of about

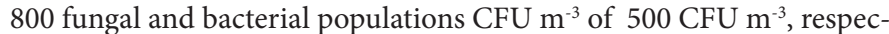
tively. Burge et al. [20] collected volumetric culture plate air samples on 14 occasions over the 18 -month period immediately following a building occupancy. On each sampling occasion, the authors collected duplicate samples from three sites on three floors of the building, and an outdoor sample. Fungal concentrations indoors were consistently below those outdoors, and no sample clearly indicated fungal contamination in the building, although visible growth appeared in the ventilation system during the course of the study.

Regardless of the resolution considered, all the monitored environments in CDA/MAST presented acceptable microbiological concentrations, both for fungal, bacterial or total populations. This supports the hypothesis that human comfort is achieved, with respect to the presence of microorganisms in the air-conditioned areas monitored. Regarding the transfer of documentary collections of MAST or its maintenance in these areas, it is needed a complementary identification of bacterial and fungal species found, only to confirm if these species are those with a more cellulose degrading ability, despite their very low concentration. Both from the standpoint of human comfort, as well as the point of view of a possible cellulolytic activity on the documents a deeper investigation, involving their biochemical identification and genotypic confirmation that would render more conclusive results about archives biodeterioration.

\section{Conclusions}

In none of the room of CDA/MAST microbiological contamination was superior to that obtained in the external environment. This indicates that the ventilation system and air conditioning and/or the presence of humidity, do not favor the concentration of microbial species in these environments. Regarding the adequacy of the microbiological parameters according to Anvisa Resolution 176/2000 [21], all environ- ments can be considered suitable for movement of staff, since the relationship between microbial populations in the internal and external areas is not higher than 1.5. Other Resolutions based on the same parameters, including the World Health Organization [22], indicated that there was no incidence of fungal or bacterial microbial populations in numbers that justify the need for decisions in relation to the operation of ventilation systems or relative humidity control. Environments being monitored are intended to keep scientific and historical archives, and this deserves a more thorough investigation regarding the identification of microbial species isolated in order to identify the possible occurrence of species that have the cellulolytic enzyme complex, which may jeopardize the long-term permanence of historical documents, by direct biochemical action or through a possible actions of secreted metabolites.

\section{Acknowledgements}

Authors thank the Ministry of Science and Technology and CNPq for support to conduct this work.

\section{Ethical Standards} Brazi

The authors declare that these experiments comply with the current laws of

\section{References}

1. Abe K (2010) Assessment of the environmental conditions in a museum storehouse by use of a fungal index. Intnl Biodet Biodegr 64: 32-40.

2. ABNT Associação Brasileira de Normas Técnicas, NBR 6401 Central installations of air-conditioners for human comfort - Basic project parameters (In Portuguese), 1980

3. Aira MJ, Jato V, Stchigel AM, Rodrigues-Rajo FJ, Piontelli E (2007) Aeromycological study in the Cathedral of Santiago de Compostela (Spain). Intnl Biodet Biodegr 60: 231-237

4. ANSI/ASHARAE, American Society of Heating, Refrigerating and Air-Conditioning Engineers, 62. Standard-Ventilation for Acceptable Indoor Air Quality, 1990.

5. ANVISA, Agência Nacional da Vigilância Sanitária, Resolução n. ${ }^{\circ} 176$ de 24/10/2000.

6. Bergey (2005) Bergey's Manual of Systematic Bacteriology 2nd Edition. Volume 2, The Proteobacteria, Garrity, GM Brenner, DJ Krieg, NR. e Staley, J. T. (eds.).

7. Bortoletto ME (1998) Fungal contaminations in indoor environments: the case of Manguinhos Library (In Portuguese). Rev Brasindoor 2:1-7.

8. Brickus LSR, Cardoso JN, Aquino Neto FR (1997) Determination of suspended particulate materials in indoor and outdoor áreas of a commercial building in Rio de Janeiro City (In Portuguese). Rev Brasindoor 2:12-22.

9. Burge HA, Pierson DL, Groves TO, Strawn KF, Mishra SK (1999) Dynamics of airborne fungal populations in a large office building. Curr Microbiol 40:10-16.

10. Dantas EHM (1998) Air conditioner: villain or ally? A critical review. Rev Brasindoor 2:4-14.

11. Giannantonio DJ, Kurth JC, Kurtis KE, Sobecky PA (2009) Effects of concrete properties and nutrients on fungal colonization and fouling. Intnl Biodet Biodegr 63:252-259.

12. Hoang CP, Kinney KA, Corsi RL, Szaniszlo PJ (2010) Resistance of green building materials to fungal growth. Intnl Biodet Biodegr 64:104-113.

13. Hood MA (1990) Gram-negative bacteria as aerosols. In: Biological contaminants in indoor environments. Edited by PR Morey, JC Feeley, JA Otten. American Society for Testing and Materials, Philadelphia, Pennsylvania, USA.

14. Hyvarinena A, Meklina T, Vepsalinena A, Nevalainen A (2002) Fungi and actinobacteria in moisture-damaged building materials-concentrations and diversity. Intnl Biodet Biodegr 49:27-37.

15. Kulcsar-Neto F, Siqueira LFG (1999) Reference standars for the analysis of indoor air microbiological quality. References for health quality in Brazil (In Portuguese). Rev Brasindoor 2:4-21.

16. Nielsena KF, Holma G, Uttrupa LP, Nielsen PA (2004) Mould growth on building materials under low water activities. Influence of humidity and temperature on fungal growth and secondary metabolism. Intnl Biodet Biodegr 54: 325-336. 
Citation: Augusto da Costa AC, da Silva Lino LA, Hannesch O (2011) Total Microbial Populations in Air-Conditioned Spaces of a Scientific Museum: Precautions Related to Biodeterioration of Scientific Collections. J Bioprocess Biotechniq 1:106 doi: 10.4172/2155-9821.1000106

Page 6 of 6

17. Jaffal AA, Banat LM, El Mogheth AA, Nsanze $H$, Bener A, Ameen AS (1997) Residential indoor airborne microbial populations in the United Arab Emirates. Enviornment international 23: 529-533

18. Mesquita N, Portugal NMA, Videira S, Eccheverria SR, Bandeira AML, et al. (2009) Fungal diversity in ancient documents. A case study on the Archive of the University of Coimbra. Intnl Biodet Biodegr 63: 626-629.

19. Pasanena AL, Kasanena JP, Rautialla S, Ikaheimoa M, Rantamaki J, et al. (2000) Fungal growth and survival in building materials under fluctuating moisture and temperature conditions. Intnl Biodet Biodegr 46: 117-127.
20. Shelton BG, Kirkland KH, Flanders WD, Morris GK (2002) Appl Environ Microbiol 2002 68:1743-1753.

21. Toth C (1992) Microbials in the overall context of indoor air quality investigation. Proceedings of the First Annual IAQ. Conference and Exposition 255-259.

22. World Health Organization. Indoor air quality: biological contaminants; Copenhagen, Denmark, 1983 (European Series $n^{\circ} 31$ ). 